\title{
The Impact of Applying Quality Standards on Improving Environmental Tourism Services for Natural Reserves in Southern Jordan
}

\author{
Lamees Turkey Al-Khawaldeh ${ }^{1} \&$ Ghazy Ali Al-Badayneh ${ }^{2}$ \\ ${ }^{1}$ Dana Biosphere Reserve and Environmental Education Supervisor, Jordan \\ ${ }^{2}$ Faculty of Business, Business Administration Department, Tafila Technical University, At-Tafila, Jordan \\ Correspondence: Ghazy AL Badayneh, Faculty of Business, Tafila Technical University, AT-Tafila, P.O.Box179, \\ Tafila, 66110, Jordan. E-mail: Ghazy70312005@yahoo.com
}

Received: March 31, 2021

doi:10.5539/ijbm.v16n7p119

Accepted: April 25, 2021

Online Published: June 21, 2021

\begin{abstract}
This study aimed at identifying the impact of applying quality standards on improving environmental tourism services of natural reserves in southern Jordan, the study population consisted of (5946) visitors from all natural reserves in southern Jordan. The descriptive analytical survey method was used, the study conducted a field survey using a questionnaire which was distributed to a six hundred (600) visitors from the nature reserves in southern Jordan who were chosen by a simple random method. The results of statistical analysis using the statistical program for social sciences (SPSS) showed that there is a statistically significant impact of applying quality standards (security and safety, accessibility, and Originality) on improving environmental tourism services in natural reserves in southern Jordan, in light of the study results, the study recommends the administration of natural reserves in southern Jordan to develop a plan to ensure the improvement of its eco-tourism services, by constantly applying quality standards.
\end{abstract}

Keywords: quality standards, environmental tourism services, natural reserves

\section{Introduction}

The Hashemite Kingdom of Jordan is distinguished by its geographical and strategic location providing it with a biological and climatic diversity, which makes it an ecological tourist destination for various visitors of the world, it is unique with various natural landscapes that suit most of those coming to visit it, it is considered one of the most important Arab countries to attract all types of tourism from around the world throughout the year especially ecotourism. The Hashemite Kingdom of Jordan is one of the first countries interested in the ecotourism industry, as most studies indicated that it appeared in the early eighties of the last century, the ecotourism industry is a major tributary of the gross domestic product, and it is one of the most important economic sectors (Al-Muhairat, 2011).

Environmental tourism has been defined as protecting the environment to achieve sustainable development through the optimal use of natural resources (Masani, 2019), the economic importance of tourism lies in its connection with the global in terms of technological progress in information, communication and transportation which provided easy travel and mobility for visitors, from the economic point of view it led to attracting capital, and accelerating the volume of foreign investment, especially related to the tourism industry because of the availability of its various types of components, and its entry into the field of competition with the petroleum industries for some countries if they were optimally exploited, with the emergence of modern technology in the field of global tourism that requires the development and improvement of tourism services to be at its highest levels by using international technologies to apply quality standards for excellence and advancement, accordingly, the tourism sector has to fulfill the desires of visitors and their needs for the tourism services provided to them, (Jassim and Jabouri, 2017).

\subsection{The Study Problem and Its Questions}

With the spread of ecotourism internally and externally, the flocking of visitors from most parts of the world, and the emergence of a strong global competition in attracting tourists; It becomes imperative for the tourism sector 
in Jordan to provide what qualifies it to enter the global competitiveness, and the study noted through its work in the field of ecotourism in the Dana Biosphere Reserve that visitors to the reserve are of most nationalities of the world; This gives visitors of the reserve the pattern of international tourism, which indicates the need to pay attention to the application of quality standards to meet the desires and needs of visitors coming to the natural reserves in Jordan in general and the south in particular.

The problem of the study is crystallized by answering the following main question: What is the impact of applying quality standards on improving environmental tourism services for nature reserves in southern Jordan?

This question is divided into the following sub-questions:

1. What is the level of the respondents' perceptions of implementing the quality standards for natural reserves in southern Jordan?

2. What is the level of the respondents' perceptions of improving ecotourism services for the nature reserves in southern Jordan?

\subsection{The Importance of Studying}

Scientific importance: This study seeks to research the impact of applying quality standards on improving environmental tourism services for the natural reserves in southern Jordan, and working to enrich the knowledge dimension in this aspect in a way that serves academics and students in the field of administration, and provides the Arab library with knowledge related to the study variables as it is the relevant variable to improve the eco-tourism services of the nature reserves in southern Jordan.

Practical importance: Presenting recommendations and suggestions to higher administrations in this vital sector to develop and improve tourism services, and directing them towards strengths, and weaknesses to improve them, and to find viable alternatives and solutions in light of rapid changes, and to achieve strong competition in this field, while attracting large numbers of visitors and attract them from different parts of the world

\subsection{Objectives of the Study}

The research seeks to achieve the following objectives:

1. Discussing and analyzing theoretical concepts related to implementing quality standards and improving environmental tourism services.

2. Defining and describing the impact of the dimensions of the application of quality standards on improving ecotourism services.

3. Determining the level of application of quality standards in improving eco-tourism services in the natural reserves in southern Jordan.

4. Presenting a number of recommendations, based on the results of the study, and making use of them.

\subsection{Study Hypotheses}

In light of the study problem and its objectives, the study hypotheses were formulated as follows:

HO1: There is no statistically significant impact at $(\alpha \leq 0.05)$ for the application of quality standards (Accessibility, security and safety, and Originality) on improving environmental tourism services in the nature reserves in southern Jordan.

The following sub-hypotheses emerge from the main hypothesis:

HO1.1: There is no statistically significant impact at $(\alpha \leq 0.05)$ for applying the (Accessibility) criterion on improving environmental tourism services in the natural reserves in southern Jordan. HO1.2: There is no statistically significant impact at the level of significance $(\alpha \leq 0.05)$ for applying the (security and safety) criterion on improving environmental tourism services in the nature reserves in southern Jordan.

HO1.3: There is no statistically significant impact at the level of significance $(\alpha \leq 0.05)$ for applying the (Originality) criterion on improving environmental tourism services in the nature reserves in southern Jordan.

\section{The Theoretical Framework and Previous Studies}

\subsection{Quality}

Al-Nuaimi, 2009 who is referred to in the study of Abdel Mohsen (2017) believes that quality is one of the most important pillars of success for any organization to obtain customer satisfaction, gain competitive advantage and increase market share. The American Quality Association defined it as a set of characteristics and the overall advantages of the product and service, and its ability to meet the customer's desires. The quality came to meet 
the customer's needs as expected, as it was defined with the specifications of the product and services and the extent of their conformity with the special standards of these services, as indicated by (Al-Afandi and Muhammad, 2019) because of the importance of quality in our lives, and its great appearance in all areas of life, and with the presence of international competitions; It is necessary to define the concept of quality in order to access the services that every user of these services wants to obtain. In the study of( Al-Jubouri, 2019) referred to in the study of (Ammar, 2019), the definition of quality came to appear through reaching all the requirements of the visitor, and we take into account that the initial beginnings of the provision of services shall be catered to the visitor.

\subsubsection{Quality Attributes}

The study of Hamad, Saleh and Hammadi (2019) indicated the quality features that are applied in order to reach the highest desirable degrees, including that quality constitutes all the complete activities of any facility, and is the basis for both the intellectual and administrative aspect, where quality depends on the participation of all the organization's employees ; as there is no quality unless all levels and systems cooperate in an organized and effective manner.

Quality considers "the commitment to provide services, with the principle of continuity, competition and teamwork in order to achieve them is most important for service providers and customers (Mahmood \& Ahamed, 2014), and meeting the customer's needs in terms of high quality services and goods is a culture (Saad allah \& Awad, 2016)

\subsubsection{Quality Objectives}

Bin Harath and Hakima's study (2018) indicated that the quality objectives lie in two main objectives, the first of which is quality control, as it relates to the special standards in any facility at all levels that it seeks to maintain, and the second: is to improve quality, which is to obtain the minimum level of mistakes with regard to providing services to obtain the highest levels of customer satisfaction.

Accordingly; several classifications of quality objectives have been developed, which varied according to their purpose, and what we expect to achieve from them, they are goals that are concerned with the facility external affairs, the other goals revolve around what is related to the facility, such as: the wishes of visitors and competition (Namin, 2017), on the one hand there are goals represented in the capacity, effectiveness and portability of operations from the point of view of controlling it, while some other goals focus on the organization in terms of its rapid response to any changes that may occur, in addition, there are goals specific to employees in terms of experience, skill and capabilities (Al-Rumaidi \& Talhi, 2018).

\subsubsection{Quality of Services}

The quality of services is one of the most important elements that the customer wishes to obtain, it serves as a compass that directs the behavior to deal with the institution that provides the service, whenever the institution innovates new complementary services with excellence in providing them, this will contribute to strengthening the basic service, and motivate the customer to return again, which is an evidence of customer satisfaction with the service provided (Hamid, Hussein and Abdullah, 2017). Therefore, the concepts of quality of services differed and varied from one person to another according to their purpose, and the service that meets their desires, as they were defined by several definitions, as mentioned in a study (Saad allah and Awad, 2016).

The researchers believe that the quality of services is a link and interaction between service providers and service recipients who work on a comparison between the service provided and what they expect.

\subsubsection{The Importance of Quality of Services}

Fundy 2012 who was referred to in the Wardi (2020) study believes that simplicity in providing quality of services is a good level in providing service that enables the customer to reach satisfaction with his expectations, and that good management of service quality contributes significantly to achieving customer satisfaction and loyalty to the facility, and quality is an additional advantage and a special motivation for clients in forming a long-term mutual relationship with the institution.

The quality of services plays an important role in developing the competitive advantage in business service, especially tourism, to improve sustainable development, focus must be placed on measuring performance, customer service, effective marketing, employee training, and also improving the efficiency of operations in service production (Bahat, 2012).

\subsubsection{Quality Standards}

The quality standards, as indicated by the Ammar study (2019), lie in competence, which includes the 
professionalism of workers, reliability, which means regularity in the performance of the worker with the presence of security and at a constant rate, as well as the rapid response to the requirements of the customer on the side of the establishments at all times and places, accessibility, and good understanding, The facility must understand and improve the customer's requirements, as the facility seeks to communicate with customers in an understandable and clear language in order to be able to maintain them on the one hand, and the reputation of the facility on the other hand, with the aim of creating both credibility with customers and security for workers, maintaining courtesy, level of accuracy, and commitment to the quality of the tourism product, which is expressed in the set of contributions and processes of stakeholders, whether in the public or private sector. Ensuring safety and security for tourists is a key factor in achieving the concept of quality of the tourism product. The researchers believe - from their point of view - that the tourism sector is one of the most important sectors in the world and is characterized by vitality, and the economies of the world countries are based on it, it is considered a means of cultural exchange between the peoples of the world, which puts this sector in great challenges, especially in the application of quality standards at its highest levels, and because the judgment can only be made by the customer satisfaction with these tourism services.

\subsection{Tourist Services}

Nour al-Islam (2017) believes that the concept of tourism services is a group consisting of various services and products in its final form provided to customers and visitors by any tourism sector. Views differed in defining the concept of services, as the American Shopping Association defined it as a benefit offered for sale and distributed by the service production unit for a specific individual, group of individuals, or other destination that entails intangible outputs, from the previous definition we can conclude that the tourism product is services that the service production unit works to market in the best way, without these services the tourism sector cannot be sustainable, as the services seek to meet and satisfy the visitors' desires (Khubaizi \& Dreer, 2020).

Christiane gronroos believes that services are a specific activity or group of activities that are not perceived, do not require direct interaction with customers and are the solution to the problems of some customers, while Philip kotler, defined it as a business or an activity subject to exchange, and it is characterized by lack of sensitivity and not subject to the ownership of a specific person, moreover, it can or can't be associated with a specific product (Othman \& Amina, 2019).

\subsubsection{The Importance of Tourism Services}

Tourism services in various countries face difficulties and challenges as a result of rapid changes, such as the emergence of epidemics, terrorism, economic recession, the emergence of the concept of globalization, strong competitions, and the lack of demand for the tourism sector which adversely affected the tourism activity, therefore it was necessary to pay attention to the quality of tourism services to distinguish them from the rest of the competing sectors in the same field, by providing services that meet the desires and needs of customers. In addition, consideration was given to the sustainability of the tourism sector by developing creative marketing strategies that are consistent with the available resources and the purpose of the work (Rice, 2018).

Al-Raqqad (2008) confirmed that the role played by the tourism services sector is increasing with the increase in the country's overall economy in terms of its effective participation and increase in the total public income, as well as its contribution to creating diversified job opportunities for the youth.

Ali \& Jeon (2017) believes that there is a close relationship between the quality in providing tourism services and the degree of happiness, satisfaction and acceptance of visitors, which will be reflected in the future on tourism institutions and facilities with a positive return, it is considered as a weapon and savings that is stored and used in times of need and crises, the diversity of social classes has increased because of the social services that are an attempt to provide various tourism services that meet the needs and desires of these different classes of people, these services include, for example, tourism, education, banking services, and other services that facilitate human life (Merhej \& Bwatt, 2015).

\subsubsection{Natural Reserves}

The concept of natural reserves is one of the concepts that appeared recently, it was defined at the Stockholm Conference in 1972 as an ecological unit consisting of land and water and has a set of characteristics and features, it is one of the distinct biogeographical forms, and it also forms a unit of productive ecology (Mehirat, 2011).

It was defined in the past decades as parks and certain areas that fall within specific conditions, such as determining a place to walk, laws of hunting, watching animals, and studies pertaining to plants, as they were identified by geologists and geographers, until a new definition of the nature reserve appeared as an area of land located by the government, it is characterized by a tremendous and distinctive biological diversity, it has a 
civilizational and cultural heritage that is different from the rest of the regions. Nature reserves formed approximately (6\%) of the earth's area (Riyadh, 2018).

\subsection{Previous Studies}

The study of Al-Atoum, Ayham (2020) entitled: The "digital tourism reputation of Jordan" is an important opportunity that can be invested. The study aimed at measuring the extent of awareness among decision makers in the public and private sectors of the role of social media in stimulating Jordanian tourism, The study sample consisted of (650) people working in the tourism sector, which consisted of the Ministry of Tourism and the Tourism Sector Revitalization Authority from the government sector, while from the private sector is the Jordanian Hotels Association, tourist offices, and Jordanian royal lines. One of the most important findings of the study is that the challenges facing this type of tourism marketing in light of the absence of specialized legislation and laws is in marketing through social media, and that there are deficiencies in electronic marketing, especially among the managers of the pages of the sites, as well as the decrease in listening to customers and social communication. The researcher recommended that the digital reputation of Jordan is a golden opportunity that can be invested to activate one of the most prominent productive sectors in the Hashemite Kingdom of Jordan.

Souad and Dowly study (2020) entitled: "Interest in tourism services as one of the pillars of the advancement of the tourism sector in the state of Bashar - Algeria", the study aimed at clarifying the most important tourism services in the state of Bechar, and the ways to develop them, it aimed at showing the vast tourism capabilities of the Bashar state and how to use it optimally. The study used the descriptive and analytical method. The study used the descriptive and analytical approach, the questionnaire was distributed to (50) visitors from the state of Bashar, the study concluded with the most important results that most visitors to the state of Bashar are calling for an increase in interest in basic tourism services, such as: infrastructure, food and drink services, accommodation services, and tourism offices. In order to develop this sector, the study recommended the necessity of using modern and advanced technologies in the field of tourism services, focusing on training of workers in the tourism sector, and developing a strategic plan for marketing tourism services.

Ammar study (2019) entitled: "The reality of the quality of tourism services in the Algerian institution," the study aimed at assessing the level of quality of tourism services provided by the institutions under study from the customers' point of view, based on a set of quality dimensions, the study sample consisted of (240) visitors to hotels in Bou Saada, Algeria. The researcher used the descriptive and analytical approach through the questionnaire tool to collect data, among the most prominent results of the study was the evaluation of visitors to the quality of the tourism services provided to them at a high level, with deficiencies in quality indicators, as well as the contribution of the quality of services to improving the reputation of institutions among visitors at the present and future time. The study recommended further research on assessing the quality of tourism services from the employees' point of view.

Hamad, Saleh and Hammadi (2019) study entitled: "Quality of Tourism Services between Reality and Ambition: An Analytical Study in Premium Class Hotels" in Iraq represented in (Sheraton, Babylon, and Aubrey) in Iraq, the study sample consisted of these three hotels of excellent rating. The researcher used the descriptive analytical approach through the questionnaire tool to collect data. One of the most prominent results of the study was that the surveyed hotels suffer from clear problems in using the quality dimensions of the tourism services necessary to achieve outstanding performance, through the dimensions of reliability and response that were negative and far from the visitor's expectations, as well as affirmation and empathy was weak, while the tangibility result was moderate. The study recommended that the quality dimensions of tourism services should not be merely promises from higher administrations that contradict the expectations of visitors, and that they may lose the trust and confidence of these organizations in the future.

Daskalaki and Hatzithomas (2020) titled "Service quality, visitor satisfaction and future behavior in the museum sector" aimed at testing the applicability of the service quality dimensions according to the (SERVPERF) model in the Greek museums sector, comparing the effectiveness of the SERVPERF dimensions and predicting visitor satisfaction and future expectations. Among the most prominent results of the study was that the five dimensions (tangibility, reliability, responsiveness, empathy, and reliability) of the quality of tourism services can determine a high degree of visitor satisfaction, and their future expectations, the study showed a statistically significant impact in the tangible effect on visitor satisfaction and future expectations.

Vu et al (2020) study entitled: "Cultural Contact and Service Quality Components Impact on Tourist Satisfaction" aimed at identifying the components of service quality in specific tourist destinations and finding the relationship between cultural contact and service quality for the Mekong Delta region in Vietnam. The study sample consisted of (350) visitors from tourist hotels were chosen randomly, the study used quantitative and qualitative 
research method, among the most important results of the study was that all factors are important in the components of the quality of services, including security, safety, infrastructure, human resources, and the natural environment, as well as the price, which in turn affects the satisfaction of visitors.

Al-Hazmia (2020) study entitled "A study on the dimensions of the quality of tourism services in the Kingdom of Saudi Arabia", which aimed at determining the relationship between the quality of services provided to the customer and the dimensions of the quality of services in the hotel industry in the city of Al-Kharj in the Kingdom of Saudi Arabia. The study consisted of (50) visitors who visited tourist hotels, they were chosen randomly, the study followed the descriptive analytical approach through the questionnaire tool. The most prominent results of the study concluded that there is a great correlation between the quality of service provided by the hotel establishments in Al-Kharj Governorate and the dimensions of the quality of services, which affects the satisfaction of customers who use these services, the study recommended attention to training workers in the hotel sector, qualifying them and strengthening the team spirit among them, as well as the need to pay attention to tangible aspects of hotel services, and strengthening the relationship between the service provider and the beneficiaries.

Jyoti and Gogoi (2020) study entitled: "Service quality measure: how impacts customer satisfaction and loyalty. The study aims at finding out the factors that affect customer satisfaction and show the relationship between customer satisfaction and customer loyalty, the study used the descriptive analytical approach, the study was conducted on visitors of Assam and Meghalay state. The questionnaire was distributed to (408) visitors randomly, and the most important results were that the service quality standards of tangibility, empathy, reliability and responsiveness have a positive impact on customer satisfaction and loyalty, the study recommended a good understanding of quality dimensions in order to reach the competitive advantage that achieves visitor satisfaction and loyalty to the place.

\section{Methodology and Design}

\subsection{Study Method}

The study was based on the descriptive and analytical survey method, which includes conducting a desk survey by referring to references and sources to build the theoretical framework of the study, and a field survey to collect data using the study tool (questionnaire), which was developed and distributed to the sample members and analyzed statistically.

\subsection{Study Population and Sample}

The study community consisted of all the visitors to the natural and environmental reserves in southern Jordan, whose number is (5946) visitors according to the statistics of the reserves on January 1/2020 distributed over the reserves, (2779) visitors of Dana Biosphere Reserve, (917) of the Mujib Biosphere Reserve, (2100) from the Aqaba Bird Observatory, and (150) from the Faifa Nature Reserve, the study questionnaire was distributed to six hundred (600) visitors. Five hundred and thirty (530) questionnaires were recovered, but the study was unable to retrieve (70) of them, while (30) questionnaires were excluded because they were not valid for the purposes of statistical analysis, the number settled on (500) questionnaires distributed as follows: (190) visitors from the Dana biosphere reserve (130) visitors from the Mujib Biosphere Reserve, (110) visitors from the Aqaba Birds Observatory, and (70) visitors from the Faifa Nature Reserve. 
Table 1. Demographic data for the study sample

\begin{tabular}{llll}
\hline Variables & Categories & Frequencies & Percentages \\
\hline Sex & Male & 330 & $66 \%$ \\
Total & Female & 170 & $34 \%$ \\
Age & - & 500 & $100 \%$ \\
& $18-30$ & 120 & $24 \%$ \\
& $31-40$ & 180 & $36 \%$ \\
Total & $41-50$ & 90 & $18 \%$ \\
Qualification & 51 and above & 110 & $22 \%$ \\
& - & 500 & $100 \%$ \\
& High school and below & 90 & $18 \%$ \\
Total & Intermediate diploma & 150 & $30 \%$ \\
Nationality & Bachelor & 210 & $42 \%$ \\
& Postgraduate & 50 & $10 \%$ \\
& - & 500 & $100 \%$ \\
Total & Jordanian & 100 & $20 \%$ \\
Duration of stay & A non-Jordanian Arab & 150 & $30 \%$ \\
& Foreigner & 250 & $50 \%$ \\
& - & 500 & $100 \%$ \\
& one day & 90 & $18 \%$ \\
Total & $2-5$ & 160 & $32 \%$ \\
\hline & $6-10$ & 120 & $24 \%$ \\
& 11 days or more & 130 & $26 \%$ \\
& - & 500 & $100 \%$ \\
& & & \\
& & & \\
& & &
\end{tabular}

\subsection{Study Tool and Methods of Collecting Data and Information}

A questionnaire was developed based on Likert's five-volume scale (Likert) consisting of five options, ranging from completely agree to never agree, with a relative weight (1-5). The questionnaire was divided into two main groups: the first concerned with the personal and job data of the respondents, while, the second with the core subject of the research, it includes a set of items that relate to three basic axes for the independent variable (criteria for the quality of environmental tourism services, (namely: security and safety, Accessibility, and originality).

\subsection{Tool Reliability}

The reliability coefficient was extracted according to the Cronbach alpha equation to ensure the internal consistency in its final form and for each variable in all its dimensions. The reliability values were high and indicate the reliability and consistency between the instrument's items. The following table (2) shows the values of the stability coefficient:

Table 2. The values of the reliability coefficients and the internal consistency of the study variables

\begin{tabular}{lll}
\hline Item No. & Dimension name & Reliability coefficient (Cronbach alpha) \\
\hline $1-5$ & Accessibility & .862 \\
$6-11$ & Safety and Security & .844 \\
$12-17$ & originality & .871 \\
$1-17$ & Independent variable (criteria for the quality of & .861 \\
& environmental tourism services) & \\
$18-32$ & Dependent variable (environmental tourism services) & .896 \\
\hline
\end{tabular}

Checking the normal distribution of the study variables:

The kolmogorov_smirnov test was performed for the purposes of verifying that the study data are free from statistical problems, and to ensure the availability of a natural distribution in the data as shown in table (3). 
Table 3. The normal distribution of the study variables

\begin{tabular}{llll}
\hline variable & kolmogorov_Simonov & Sig & Result \\
\hline Accessibility & 0.064 & 0.131 & It follows the normal distribution \\
Safety and Security & 0.081 & 0.164 & It follows the normal distribution \\
originality & 0.142 & 0.126 & It follows the normal distribution \\
Tourist services & 0.089 & 0.214 & It follows the normal distribution \\
\hline
\end{tabular}

\subsection{Statistical Treatment}

The study relied on the statistical package of social sciences (spss.19) in the statistical analysis through the use of statistical methods to describe the characteristics of the sample based on the frequencies and percentages to answer the study questions.

\section{The Result}

The following is a presentation of the results of the descriptive statistics of the data, which is the value of the means and standard deviations of the study dimensions and the items that make up each dimension:

First: The Accessibility criterion.

Table 4. Means, standard deviations, and the relative importance of the study sample responses to the accessibility criterion

\begin{tabular}{|c|c|c|c|c|}
\hline Item No. & The criterion of Accessibility & Mean & Standard dev & Relative importance \\
\hline 3 & $\begin{array}{l}\text { Environmental tourism services are provided in a correct way } \\
\text { for the first time. }\end{array}$ & 3.47 & 1.39 & Intermediate \\
\hline 4 & $\begin{array}{l}\text { The nature reserve simplifies work procedures as much as } \\
\text { possible to ensure speedy provision of services. }\end{array}$ & 2.81 & 1.01 & Intermediate \\
\hline 1 & $\begin{array}{l}\text { The staff easily and conveniently answers visitors' comments } \\
\text { and inquiries. }\end{array}$ & 2.68 & 1.07 & Intermediate \\
\hline 2 & $\begin{array}{l}\text { The nature reserve is obligated to provide ecotourism services } \\
\text { on schedule. }\end{array}$ & 2.63 & 1.18 & Intermediate \\
\hline \multirow[t]{2}{*}{5} & $\begin{array}{l}\text { The nature reserve uses modern technology to provide its } \\
\text { eco-tourism services to visitors. }\end{array}$ & 2.59 & 1.11 & Intermediate \\
\hline & The total mean & 2.83 & 1.15 & Intermediate \\
\hline
\end{tabular}

Table 4 shows that the means of the study sample's answers to the items of the Accessibility criterion were of medium importance, as the overall means reached (2.83) and the items (3), which refers to "The environmental tourism services are provided in a correct way the first time," is the highest among the items with a mean of (3.47). Its relative importance was intermediate, while the item (5), which refers to "The Nature Reserve uses modern technology to provide its environmental tourism services to visitors," came with a mean of (2.59), and its relative importance was intermediate.

These results indicate that all the means reached by the study were higher than the mean of the limits adopted by the study when commenting on the means on all statements.

Second: Standard of safety and security. 
Table 5. Means, standard deviations, and the relative importance of the study sample responses to the safety and security criterion

\begin{tabular}{lllll}
\hline Item No. & The criterion of Safety and security & Mean & Standard dev & Relative importance \\
\hline 6 & $\begin{array}{l}\text { The nature reserve provides with public safety tools } \\
\text { and equipment in all its facilities. }\end{array}$ & 3.58 & 1.27 & Intermediate \\
& $\begin{array}{l}\text { Visitors feel safe and secure when walking on the } \\
\text { tourist lanes (without a guide). }\end{array}$ & 3.51 & 1.41 & Intermediate \\
& $\begin{array}{l}\text { Visitors are safe with their equipment and personal } \\
\text { tools while visiting the reserve. }\end{array}$ & 2.81 & 1.19 & Intermediate \\
& $\begin{array}{l}\text { The reserve has a first aid service in the event of any } \\
\text { accident. }\end{array}$ & 2.68 & 1.17 & Intermediate \\
& $\begin{array}{l}\text { The nature reserve provides health flyers and guide } \\
\text { boards to maintain safety and security. } \\
\text { Visitors feel safe and secure when walking the tourist } \\
\text { lanes (with guide) }\end{array}$ & 2.61 & 1.03 & Intermediate \\
& The total mean & 2.35 & 1.10 & Intermediate \\
& & 2.92 & 1.19 & Intermediate \\
\hline
\end{tabular}

Table 5 shows that the means of the study sample's answers to the items of the security and safety criterion were of medium importance, as the overall mean reached (2.92), item (6), which refers to "the nature reserve in all its facilities provides with the general safety tools and equipment" is the highest among items, with a mean of (3.58), where its relative importance was medium, while item (11), which refers to "visitors feel safe and secure when walking in the tourist lanes (with the guide)," with a mean of (2.35), its relative importance was medium.

These results indicate that all the means reached by the study were higher than the mean of the limits adopted by the study when commenting on the means on all the statements.

Third: Standard of originality.

Table 6. Means, standard deviations, and the relative importance of the study sample responses to the criterion of originality

\begin{tabular}{|c|c|c|c|c|}
\hline Item No. & The criterion of originality & Mean & $\begin{array}{l}\text { Standard } \\
\text { dev }\end{array}$ & $\begin{array}{l}\text { Relative } \\
\text { importance }\end{array}$ \\
\hline 17 & $\begin{array}{l}\text { The nature reserve provides eco-tourism services related to the region's heritage, } \\
\text { taking into account the visitors' aspirations. }\end{array}$ & 3.51 & 1.39 & Intermediate \\
\hline 13 & The staff has excellent skills in providing ecotourism services. & 3.31 & 1.43 & Intermediate \\
\hline 14 & $\begin{array}{l}\text { The nature reserve can produce eco-tourism services with high efficiency and } \\
\text { effectiveness. }\end{array}$ & 2.80 & 1.12 & Intermediate \\
\hline 16 & $\begin{array}{l}\text { The nature reserve creates distinct eco-tourism activities and procedures and } \\
\text { presents them to visitors. }\end{array}$ & 2.65 & 1.10 & Intermediate \\
\hline 15 & $\begin{array}{l}\text { The nature reserve avoids repetition in the procedures for providing tourism } \\
\text { services. }\end{array}$ & 2.52 & 1.11 & Intermediate \\
\hline \multirow[t]{2}{*}{12} & $\begin{array}{l}\text { The nature reserve derives its vision from the inspiration of nature and the } \\
\text { surrounding environment, and reflects the institutional image of their reserve. }\end{array}$ & 2.38 & 1.15 & Intermediate \\
\hline & The total arithmetic mean & 2.81 & 1.20 & Intermediate \\
\hline
\end{tabular}

Table 6 shows that the means of the study sample's answers to the items of the originality criterion were of medium importance, as the overall mean reached (2.81) and the item (17) which refers to "the nature reserve provides environmental tourism services related to the heritage of the region, taking into account the visitors' aspirations " was the highest among items, with a mean of (3.51), its relative importance was medium, while the item (12) which refers to "The nature reserve derives its vision from the inspiration of nature and the surrounding environment and reflects the institutional picture of their reserve" with a mean of (2.38), its relative importance was moderate.

These results indicate that all the means that were calculated were higher than the mean limits adopted by the study when commenting on the means on all statements.

The variable of environmental tourism services: 
Table 7. Means, standard deviations, and the relative importance of the study sample responses to the environmental tourism services variable

\begin{tabular}{|c|c|c|c|c|}
\hline Item No. & Variable of environmental tourism services & Mean & $\begin{array}{l}\text { Standard } \\
\text { dev. }\end{array}$ & $\begin{array}{l}\text { Relative } \\
\text { importance }\end{array}$ \\
\hline 30 & $\begin{array}{l}\text { The activities and programs offered by the nature reserve are among the } \\
\text { main factors to repeat visit. }\end{array}$ & 3.81 & 1.31 & High \\
\hline 29 & $\begin{array}{l}\text { Environmental tourism services vary in terms of activities and programs } \\
\text { (ecological paths, climbing mountains, watching birds and animals, and } \\
\text { watching the sunset). }\end{array}$ & 3.68 & 1.35 & High \\
\hline 27 & The method of providing ecotourism services matches my expectations. & 3.66 & 1.35 & Intermediate \\
\hline 25 & $\begin{array}{l}\text { The external and internal structure of the nature reserve is organized and } \\
\text { integrated. }\end{array}$ & 3.64 & 1.54 & Intermediate \\
\hline 26 & $\begin{array}{l}\text { The employees of the nature reserve speak more than one language with } \\
\text { visitors, according to their nationalities. }\end{array}$ & 3.55 & 1.43 & Intermediate \\
\hline 20 & $\begin{array}{l}\text { You get bored with types of food and repetition after two or three days of } \\
\text { your stay in the reserve. }\end{array}$ & 3.52 & 1.40 & Intermediate \\
\hline 31 & $\begin{array}{l}\text { The receptionist answered phone and e-mail in a courteous and satisfactory } \\
\text { manner. }\end{array}$ & 3.12 & 1.35 & Intermediate \\
\hline 18 & $\begin{array}{l}\text { The nature reserves promote their services through social media and on } \\
\text { their site in an attractive and elegant manner. }\end{array}$ & 2.80 & 1.05 & Intermediate \\
\hline 23 & $\begin{array}{l}\text { The staff of the nature reserve strives to maintain a long-term relationship } \\
\text { with visitors. }\end{array}$ & 2.76 & 1.02 & Intermediate \\
\hline 24 & $\begin{array}{l}\text { The nature reserve is located in an attractive location that increases the } \\
\text { number of visitors and attracts them. }\end{array}$ & 2.63 & 1.04 & Intermediate \\
\hline 28 & $\begin{array}{l}\text { The staff of the nature reserve make every effort to provide eco-tourism } \\
\text { services to satisfy the visitors. }\end{array}$ & 2.63 & 1.17 & Intermediate \\
\hline 19 & $\begin{array}{l}\text { The cost of accommodation, food and drink is satisfactory when measured } \\
\text { by the level of service provided. }\end{array}$ & 2.63 & 0.99 & Intermediate \\
\hline 22 & $\begin{array}{l}\text { The reserve provides sufficient quantities of food that are sufficient for all } \\
\text { visitors, regardless of their number. }\end{array}$ & 2.61 & 1.07 & Intermediate \\
\hline 32 & $\begin{array}{l}\text { The reserve continuously evaluates its eco-tourism services to improve the } \\
\text { level of services. }\end{array}$ & 2.59 & 1.16 & Intermediate \\
\hline \multirow[t]{2}{*}{21} & $\begin{array}{l}\text { The reserve arranges dining priorities and dates according to the number of } \\
\text { visitors to avoid crowds in the dining hall. }\end{array}$ & 2.48 & 1.00 & Intermediate \\
\hline & The total mean & 3.07 & 1.21 & Intermediate \\
\hline
\end{tabular}

Table 7 shows that the means of the study sample responses to the items of the variable environmental tourism services came with a medium importance ratio, as the overall mean reached (3.07) and item (30) which indicates "that the activities and programs provided by the nature reserve are among the main factors to repeat my visit to it " had the highest mean among items, with a mean of (3.81), its relative importance was high, whereas item (21), which refers to "the reserve arranges food priorities and dates according to the number of visitors to avoid crowds in the food court," with a mean of (2.48), its relative importance was medium.

These results indicate that all the means that were reached were higher than the mean limits adopted by the study when commenting on the means on all statements.

Results of hypothesis testing:

To verify the impact of applying quality standards on improving eco-tourism services for natural reserves in southern Jordan, each on its own, a simple regression analysis was used to test each sub-hypothesis separately, and tables (8-9) illustrate these results.

The first hypothesis test.

There is no statistically significant impact at the level of significance $(0.05 \geq \alpha)$ for applying the Accessibility criterion on improving environmental tourism services in the nature reserves in southern Jordan. 
Table 8. Simple linear regression analysis of the impact of applying the Accessibility criterion on improving environmental tourism services in nature reserves in southern Jordan

\begin{tabular}{llllll}
\hline & $\begin{array}{l}\text { R2 } \\
\text { The coefficient } \\
\text { determination }\end{array}$ & $\begin{array}{l}\mathrm{T} \\
\text { Calculated }\end{array}$ & $\begin{array}{l}\mathrm{T} \\
\text { Tabular }\end{array}$ & Significance \\
\hline $\begin{array}{l}\text { The Impact of implementing the } \\
\begin{array}{l}\text { Accessibility) standard on improving } \\
\text { ecotourism services }\end{array}\end{array}$ & 8.246 & 8.25 & 0.01 \\
\hline
\end{tabular}

The above table shows that the calculated value of $(\mathrm{T})$ reached at $(8.25)$ is higher than the tabular value of $(\mathrm{T})=$ (1.98). Therefore, the main hypothesis is rejected (the null hypothesis) and the alternative hypothesis is accepted which states that "there is a statistically significant impact at the level of significance $(\alpha \leq 0.05)$. ) to apply the Accessibility criterion to improve environmental tourism services in the natural reserves in southern Jordan. "This is confirmed by the value of the significance Sig $(0.01)$ as it is less than $(0.05)$ noting that the regression coefficient is (0.398), this indicates that the variable of the Accessibility criterion is positively affects the improvement of eco-tourism services in the nature reserves in southern Jordan.

The second hypothesis test

There is no statistically significant impact at the level of significance $(0.05 \geq \alpha)$ for applying the security and safety standard on improving environmental tourism services in the nature reserves in southern Jordan.

Table 9. Simple linear regression analysis of the impact of applying the safety and security standard on improving environmental tourism services

\begin{tabular}{|c|c|c|c|c|c|}
\hline & $\begin{array}{l}\text { R2 } \\
\text { The coefficient of } \\
\text { determination }\end{array}$ & $\begin{array}{l}\mathrm{T} \\
\text { Calculated }\end{array}$ & $\begin{array}{l}\mathrm{T} \\
\text { Tabular }\end{array}$ & B & Significance \\
\hline $\begin{array}{l}\text { The impact of implementing the } \\
\text { (safety and security) standard on } \\
\text { improving environmental tourism } \\
\text { services }\end{array}$ & 0.252 & 5.98 & 1.90 & 0.370 & 0.04 \\
\hline
\end{tabular}

The above table shows that the calculated value of (T) (5.98) is higher than the tabular value of (T) (1.90). Therefore, the main (Null- Hypothesis) is rejected and the alternative hypothesis is accepted, which states that "there is a statistically significant impact at the level of significance $(0.05 \alpha)$ for applying the security and safety standard on improving environmental tourism services in the natural reserves in southern Jordan", this is confirmed by the significance value. Sig (0.04), since it is less than (0.05), noting that the regression coefficient reached $(0.370)$. This indicates that the security and safety parameter variable positively affects the improvement of environmental tourism services in the nature reserves in southern Jordan.

The third hypothesis test:

There is no statistically significant impact at the level of significance $(0.05 \leq \alpha)$ for applying the originality criterion on improving environmental tourism services in the nature reserves in southern Jordan.

Table 10. Simple linear regression analysis of the impact of applying the originality criterion on improving ecotourism services in nature reserves in southern Jordan

\begin{tabular}{llllll}
\hline & $\begin{array}{l}\text { R2 } \\
\text { The coefficient of } \\
\text { determination }\end{array}$ & $\begin{array}{l}\mathrm{T} \\
\text { Calculated }\end{array}$ & Tabular & B \\
\hline $\begin{array}{l}\text { The impact of applying the (originality) } \\
\text { criterion on improving ecotourism } \\
\text { services }\end{array}$ & 0.256 & 6.58 & 1.96 & 00.401 \\
\hline
\end{tabular}

The above table shows that the calculated value of $(\mathrm{T})=(6.58)$ is higher than the tabular value of $(\mathrm{T})(1.96)$. 
Therefore, the main hypothesis is rejected and the alternative hypothesis is accepted which states that "there is a statistically significant impact at the level of significance $(\alpha \leq 0.05))$ to apply the (originality) criterion to improve environmental tourism services in the natural reserves in southern Jordan. This is confirmed by the value of the significance $\mathrm{Sig}(0.002)$ as it is less than $(0.05)$ noting that the regression coefficient reached $(0.401$, this indicates that the variable (the criterion of originality) positively affecting the improvement of eco-tourism services in the nature reserves in southern Jordan.

Main hypothesis

There is no statistically significant impact at the level of significance $(0.05 \alpha \alpha)$ for the application of quality standards (Accessibility, security and safety, and Originality) on improving environmental tourism services in the natural reserves in southern Jordan, to test this hypothesis, the study conducted by using multiple regression analysis to find out this impact, Table (11) shows the results.

Table 11. Multiple linear regression analysis of the impact of applying all quality standards (Accessibility, security and safety, and Originality) on improving ecotourism services

\begin{tabular}{llllllllll}
\hline $\begin{array}{l}\text { Source } \\
\text { change }\end{array}$ & $\begin{array}{l}\text { Sum of } \\
\text { squares }\end{array}$ & DF & $\begin{array}{l}\text { average } \\
\text { of } \\
\text { squares }\end{array}$ & Calculated(F) & $\begin{array}{l}\text { Tabular } \\
\text { (F) }\end{array}$ & $\begin{array}{l}\mathrm{R}^{2} \\
\text { coefficient } \\
\text { determination }\end{array}$ & $\begin{array}{l}\mathrm{B} \\
\text { Regression } \\
\text { coefficient }\end{array}$ & $\begin{array}{l}\text { Level } \\
\text { significance }\end{array}$ & $\begin{array}{l}\text { Statistical } \\
\text { decision }\end{array}$ \\
\hline Regression & 2.106 & 1 & 2.106 & 122.40 & 3.76 & .3520 & 0.580 & 0.004 & $\begin{array}{l}\text { Rejecting } \\
\text { the } \\
\text { hypothesis }\end{array}$ \\
Error & 44.36 & 69 & & & & & & & \\
Total & 87.85 & 70 & & & & & & & \\
\hline
\end{tabular}

The above table shows that the calculated value of $(F)=(122.40)$ is higher than the tabular value of $(F)(3.76)$. Therefore, the main hypothesis is rejected (the null hypothesis) and the alternative hypothesis is accepted which states that "there is a statistically significant impact at the level of significance $(0.05 \leq \alpha)$ to apply the quality standards (Accessibility, security and safety, and Originality) to improve environmental tourism services in the natural reserves in southern Jordan. It indicates that the quality standards variable (security and safety, accessibility, and originality) positively affects the improvement of ecotourism services in the natural reserves in southern Jordan.

\section{Discussion of Results}

Results related to the descriptive analysis of the quality criteria variable.

- The results showed that the means of the study sample's answers to the items of the Accessibility criterion were of medium importance, and that the natural reserves in southern Jordan provide environmental tourism services in a correct way at the first time.

- The results showed that the means of the study sample's answers to the items of the security and safety criterion were of medium importance, and that the natural reserves in southern Jordan provide in all their facilities the general safety tools and equipment.

- The results showed that the means of the study sample's answers to the items of the originality criterion were of medium importance, and that the natural reserves in southern Jordan provide environmental tourism services related to the region's heritage and take into account the aspirations of visitors.

\section{Results Related to Testing the Hypotheses of the Study}

- The results of the main hypothesis test showed a statistically significant impact at the level of significance $(\alpha \leq 0.05)$ for the application of quality standards (Accessibility, security and safety, and Originality) on improving environmental tourism services in the natural reserves in southern Jordan.

- The results of the second hypothesis test showed a statistically significant impact at the level of significance $(\alpha$ 0.05) for applying the (Accessibility) criterion on improving environmental tourism services in the natural reserves in southern Jordan.

- The results of the first hypothesis test showed a statistically significant impact at the level of significance ( $\alpha$ 0.05 ) for applying the (security and safety) criterion on improving environmental tourism services in the natural reserves in southern Jordan. 
- The results of the third hypothesis test showed a statistically significant impact at the level of significance ( $\alpha$ 0.05) for applying the (originality) criterion on improving environmental tourism services in the natural reserves in southern Jordan.

\section{Recommendations}

Based on the results obtained, the study recommends the following:

- That the natural reserves in southern Jordan take the results of the current study very seriously due to the importance of the results reached, in terms of the positive impact that their results have produced for the importance of implementing quality standards, which will be reflected positively on the level of environmental tourism services to provide with excellent environmental tourism services.

- Increasing interest in implementing the sustainability standard, which includes maintaining the continuity and sustainability of ecotourism services, as this criterion is considered the most effective in improving the level of environmental tourism services from the viewpoint of visitors to the nature reserves in southern Jordan.

- The application of quality standards is considered a wide field for competition in providing the best level of tourism services and attracting visitors, therefore, the study recommends that the management of natural reserves in southern Jordan develop a plan to ensure the improvement of its eco-tourism services by constantly applying quality standards.

- The administrations of natural reserves in southern Jordan must realize that their visitors have a high level of expectation for the level of environmental tourism services provided, which helps them to assess the actual level of their eco-tourism services, These administrations should work to achieve convergence between this expectation and what they actually provide in terms of environmental tourism services. This is to maintain the provision of services within the expectations of the visitors.

- The necessity to conduct more studies in the field of management by researchers and specialists on the most appropriate quality standards to improve environmental tourism services in the natural reserves in southern Jordan that were not included in this study.

\section{References}

Abdel, M. S. (2017). Tourism E-Marketing and its Impact on Improving the Quality of Tourism Services an Applied Study of a Sample of Tourism Companies in Baghdad.

Al-Afandi, A. T. A., \& Muhammad, B. M. A. (2019). The culture of quality and its impact on improving the level of tourism service quality: An exploratory study of the opinions of a sample of workers and customers of some tourist hotels in the governorate of Erbil. Management and Economics Journal, 25(110).

AL-Hazmia, N. (2020). A study on the dimensions of the quality of tourism services in the Kingdom of Saudi Arabia. Management Science Letters, 10(5), 1115-1120. https://doi.org/10.5267/j.msl.2019.10.030

Ali, F., Hussain, K., Konar, R., \& Jeon, H. M. (2017). The effect of technical and functional quality on guests' perceived hotel service quality and satisfaction: A SEM-PLS analysis. Journal of Quality Assurance in Hospitality \& Tourism, 18(3), 354-378. https://doi.org/10.1080/1528008X.2016.1230037

Al-Rumaidi, B., \& Talhi, F. A. Z. (2018). Environmental tourism and its role in protecting the environment in light of the National Strategy for Environmental Tourism in Egypt. Sadat City University, Egypt.

Ammar, M. (2019). The reality of the quality of tourism services in the Algerian Foundation. .University of Gilali Lyabis, Sidi Bel Abbas, Algeria.

Barakat, A. M., \& Kamil, A. N. (2011). Tourism Geography and the world's tourist regions. Al Warraq Foundation for Publishing and Distribution, Amman, Jordan.

Bhat, M. A. (2012). Tourism service quality: A dimension-specific assessment of SERVQUAL. Global Business Review, 13(2), 327-337. https://doi.org/10.1177/097215091201300210

Bin, H. H., B., \& Hakima, N. (2018). The Ecological Hotel as one of the Modern Methods in the Development of Ecotourism: Study of the Experience of the Desert Lodge Hotel. Abdel Hamid Bin Badis University Mostaganem, Egypt.

Daskalaki, V. V., Voutsa, M. C., Boutsouki, C., \& Hatzithomas, L. (2020). Service quality, visitor satisfaction and future behavior in the museum sector. Journal of Tourism, Heritage \& Services Marketing, 6(1), 3-8. https://doi.org/10.5281/zenodo.3603167

Gogoi, D., \& Jyoti, B. (2020). Service quality measures: How it impacts customer satisfaction and loyalty. International Journal of Management (IJM), 11(3), 354-365. 
Hamad, S. I., Saleh, M. M., \& Hammadi, S. F. (2019). The Quality of Tourism Services between Reality and Ambition: An Analytical Study in Premium Class Hotels (Sheraton, Babel, Aubrey).

Hamid, M. A. H., Riad, S., \& Abdullah, A. A. (2017). Improving Hotel Service Quality Performance in Accordance with British Tourist Council Standards An Exploratory Study of the Views of a Sample of Arbil Hotel Guests, Tikrit University, College of Business and Economics. Tikrit Journal of Administrative and Economic Sciences, 3(39).

Jasim, R. H., \& Al-Jubouri, F. A. M. (2017). Evaluating tourism services in light of the standards of quality of the tourism product - Karbala Hotels Model. Al-Baheth Magazine, (25).

Khubaizy, S., \& Durair, J. (2020). The role of electronic media in documenting tourism services through social networking sites, Master Thesis. Soliologia Magazine, 4(2).

Mahmood, S., Qadeer, F., \& Ahmed, A. (2014). Relationship between TQM dimensions and organizational performance. Pakistan Journal of Commerce and Social Sciences, 8(3), 662-679. Retrieved from http://hdl.handle.net/10419/188162

Masani, S. (2019). Tourism Investment as a Strategic Alternative to the Post-Petroleum Phase: - The Case Study of Algeria for the Period 1995-2014 Standard Study.

Merhej, M., \& Bowatt, G. (2015). The impact of Work Turnover on the Quality of Tourism Services. Tishreen University Journal for Research and Scientific Journals, Economic and Legal Sciences Series, 1(37).

Namin, A. (2017). Revisiting customers' perception of service quality in fast food restaurants. Journal of Retailing and Consumer Services, 34, 70-81. https://doi.org/10.1016/j.jretconser.2016.09.008

Nour al-Islam, A. (2017). The Role of Marketing Communication in Promoting Tourism Services in Algeria, Master Thesis, Faculty of Social and Economic Sciences.

Othman, K., \& Amina, K. (2019). The Impact of Internal Marketing in Tourism Organizations on the Quality of Tourism Services in Algeria, Master Thesis. Journal of Economic Sciences and Facilitation and Commercial Sciences, 2(12).

Raqqad, S. (2008). Evaluating the quality of services from the customer's point of view, Master's thesis, Faculty of Sciences, Economics and Management Sciences.

Rice, W. (2018). Tourism Awakening as a Tool to Improve Tourism Performance, Presentation of the Experience of the Ministry of Tourism in the Kingdom of Morocco, Master Thesis, University of Muhammad Khidir Biskra. Journal of Banking Financial Economics and Business Administration, 3(5).

Riyadh, M. A. (2018). Safaga and the development of ecological and mountain tourism in the Bahar region, a master's thesis. Faculty of Engineering in Matareya, Helwan University. State Journal of Architecture, Engineering and Technology, 216(1).

Saad, A., Nour, M. M., \& Awad, H. T. I. (2016). Quality of services and their impact on achieving customer satisfaction a Field study: Sudanese Islamic Bank, Savings and Social Development Bank Complementary study for a Master of Science degree in Business Administration.

Souad, D. (2020): Interest in tourism services as one of the pillars of the advancement of the tourism sector in the state of Bechar-Algeria. Journal of Economic Sciences, Management and Business Sciences, 13(1), 510-524.

Vu, N. T., Dung, H. T., Van Dat, N., Duc, P. M., Hung, N. T., \& Phuong, N. T. T. (2020). Cultural contact and service quality components impact on tourist satisfaction. Journal of Southwest Jiaotong University, 55(1). https://doi.org/10.35741/issn.0258-2724.55.1.22

\section{Copyrights}

Copyright for this article is retained by the author(s), with first publication rights granted to the journal.

This is an open-access article distributed under the terms and conditions of the Creative Commons Attribution license (http://creativecommons.org/licenses/by/4.0/). 